\title{
ANALYSIS OF FRACTIONATED FLY ASH AND SLAG AT KEMEROVO STATE DISTRICT POWER PLANT
}

\author{
Andrey S. Sysolyatin ${ }^{1}$, Ivan A. Zvingul ${ }^{1}$, and Elena Yu. Temnikova ${ }^{1, *}$ \\ ${ }^{1}$ Kuzbass State Technical University named after T.F. Gorbachev, 650000 Kemerovo, Russia
}

\begin{abstract}
Experimental results of the separation of fly ash into microspheres, magnetic and non-magnetic fractions and analysis of chemical composition of slag and magnetic and non-magnetic fractions of fly ash from Kemerovo SDPS (Russia, Kuzbass) are presented.
\end{abstract}

\section{Introduction}

Now the problem of using the wastes of coal generation companies requires immediate solution, because the active ash disposal areas are characterized by limit accumulation of ash and slag waste (ASW), increasing anthropogenic impact on the environment and increasing charges for environmental pollution. The technology for ASW processing into the conditioned ash products is suggested in [1]. The advantage of this technology is ASW maturing, when the contents of sulfur compounds, alkali oxides, humic acids, and heavy metals reduce, but this technology ignores worsening environmental conditions.

The European experience in solving the problem of waste utilizxation shows that the majority of plants use the technologies of dry ash and slag removal, they have separate warehouses for storage of ash and slag, laboratories for hourly monitoring of the produced ash, but not only coal, and systems of ash product making with no ash dumps [2]. In 2010, in all EU countries, the annual amount of ASW was estimated at 100 million tons. They are mainly used in production of building materials, civil engineering, road construction, coal mines, and pit recultivation. This also includes slag production in the amount of about 1 million tons, used mainly for blasting and road construction [3]. In addition, dry ash from Estonia is successfully sold within six years at the Russian market, and this confirms the demand for ash [2]. However, fractionated fly ash of dry sampling is in the most demand.

\section{Problem statement}

The purpose of this work is to study the chemical and mineralogical composition of fly ash and slag at Kemerovo state district power plant (SDPP) for further industrial fractionation to the valuable components.

The work tasks are separation of fly ash into microspheres, magnetic and non-magnetic fractions and analysis of chemical composition of slag and magnetic and non-magnetic fractions of fly ash.

\footnotetext{
${ }^{*}$ Corresponding author: teu.pmahp@,rambler.ru
} 


\section{Result and discussion}

For this purpose, the samples of dry fly ash and slag, obtained at combustion of coal of grade D, were taken at Kemerovo SDPP. Their pictures are shown in fig. 1.

The microspheres were removed from fly ash by wet gravitation deposition of the heavy fraction and microsphere collection from the water surface with their following drying. The magnetic and non-magnetic fractions were separated by magnetic separators in two ways: the dry and wet ones. Wet separation was carried out in water suspension of fly ash, where the magnetic fraction was concentrated in the magnetic field, with simultaneous washing of the non-magnetic fraction and drying of the obtained components. Dry separation involves the collection of the magnetic fraction by the magnetic field and its separation from the magnet [4]. As a result, the following composition of separated fractions of fly ash, presented in Table 1, was obtained. The typical types of these fractions are shown in fig. 2. Slag was not separated because it is composed of the plate-like particles of various sizes (fig. 1).
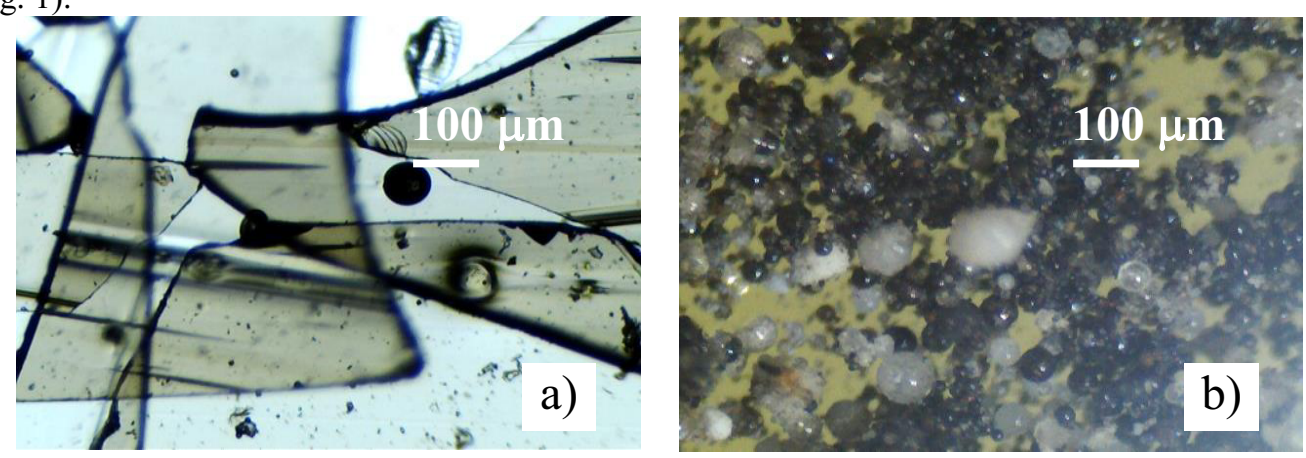

Fig. 1. Photos: a) slag; b) fly ash.

Table 1. Composition of fly ash.

\begin{tabular}{|l|c|c|c|c|}
\hline \multirow{2}{*}{$\begin{array}{c}\text { Separatio } \\
\text { n method }\end{array}$} & \multicolumn{4}{|c|}{ Composition of fly ash, \% mass. } \\
\cline { 2 - 5 } & $\begin{array}{c}\text { Microsphere } \\
\mathrm{s}\end{array}$ & $\begin{array}{c}\text { Magnetic } \\
\text { fraction }\end{array}$ & Non-magnetic fraction & Losses \\
\hline Dry [4] & 1.65 & 4.23 & 92.73 & 1.39 \\
\hline Wet & 2.46 & 3.82 & 89.18 & 4.54 \\
\hline
\end{tabular}

Table 2. The content of elements in the fractions of fly ash and slag.

\begin{tabular}{|l|c|c|c|c|c|}
\hline \multirow{2}{*}{ Element } & \multicolumn{2}{|c|}{$\begin{array}{c}\text { Non-magnetic } \\
\text { fraction }\end{array}$} & \multicolumn{2}{c|}{ Magnetic fraction } & \multirow{2}{*}{ Slag } \\
\cline { 2 - 5 } & wet & dry & wet & dry & \\
\hline $\mathrm{C}$ & 0 & 0 & 0 & 0 & 17.47 \\
\hline $\mathrm{O}$ & 47.39 & 46.67 & 42.12 & 42.78 & 40.48 \\
\hline $\mathrm{Na}$ & 1.18 & 1.31 & 1.01 & 1.08 & 1.38 \\
\hline $\mathrm{Mg}$ & 1.29 & 1.22 & 2.3 & 1.94 & 1.25 \\
\hline $\mathrm{Al}$ & 11.13 & 11.65 & 7.87 & 8.62 & 10.51 \\
\hline $\mathrm{Si}$ & 28.09 & 27.18 & 19.08 & 20.82 & 24.9 \\
\hline $\mathrm{K}$ & 2.11 & 2.08 & 1.16 & 1.38 & 1.2 \\
\hline $\mathrm{Ca}$ & 4.15 & 3.84 & 4.9 & 4.33 & 1.27 \\
\hline $\mathrm{Ti}$ & 0.59 & 0.50 & 0.29 & 0.35 & 0.18 \\
\hline $\mathrm{Mn}$ & 0.06 & 0.05 & 0.05 & 0.07 & 0 \\
\hline $\mathrm{Fe}$ & 4.01 & 4.20 & 21.22 & 17.51 & 1.35 \\
\hline
\end{tabular}


According to Table 1, at wet separation the losses in the material balance are greater than at dry separation, and the share of magnetic fraction at wet separation is less than $11 \%$

The content of elements in the non-magnetic and magnetic fractions of fly ash (for two separation methods) and slag (Table 2) was determined. The results show that despite a smaller share of magnetic fraction (Table. 1) at wet separation, the content of iron in the magnetic fraction is $21 \%$ higher than at dry separation. That is, the more concentrated product is obtained at wet separation. This can be explained by the fact that at dry separation a negative effect of static stress is observed. According to Table 2, slag contains $17.47 \%$ of carbon and has low iron content of $1.35 \%$.
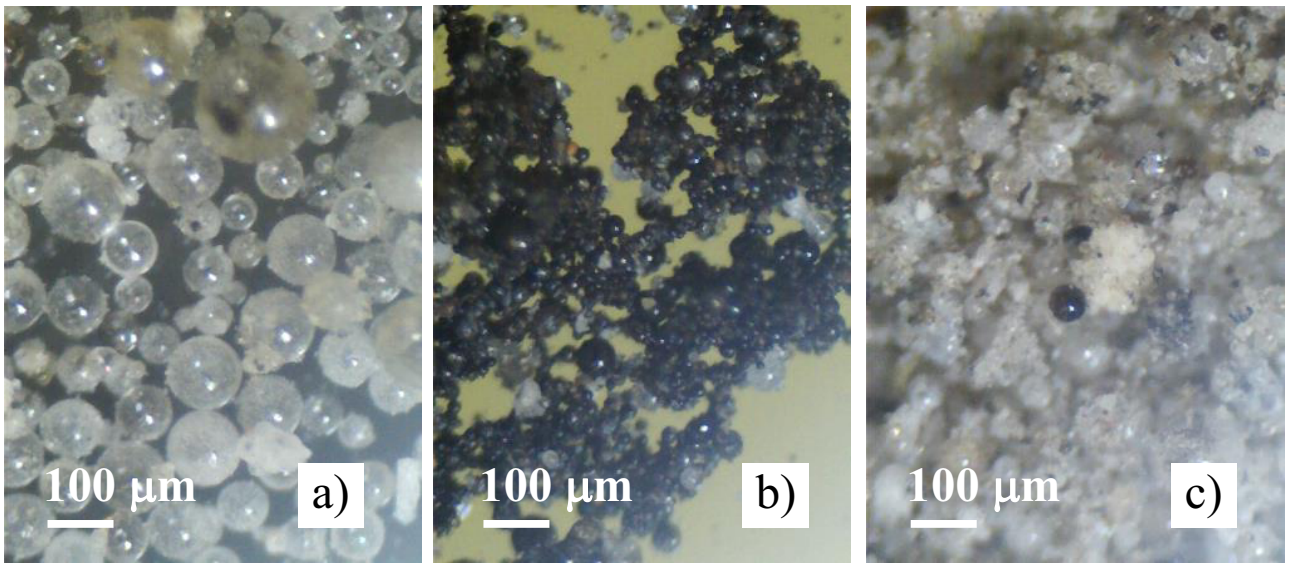

Fig. 2. Photos: a) microspheres; b) magnetic; c) non-magnetic fractions.

\section{Conclusion}

In the future trends, these results will contribute to determination of a rational flowchart of the process of separation of the magnetic fraction (iron-bearing concentrate), light fraction of fly ash (hollow microspheres) and non-magnetic fraction. The developed technology of fly ash and slag utilization will allow demonstration of the ways for improving its consumer properties and, consequently, prices. It is known that ASWs are of the industrial interest due to the chemical composition and physical-chemical properties. Ashes and and slag contain the components with unique valuable technological properties that allow their efficient use in many modern technologies. For example, according to the data of Siberian generating company, the ASW output at Kemerovo SDPP in 2012 amounted to 226 thousand tons, in 2013 it was 134 thousand tons, and in 2014, it was 136 tons. The practice shows that ASWs consist of $20 \%$ of slag and $80 \%$ of dry fly ash. In 2014, the output of dry fly ash was slightly higher than 100 thousand tons, and from this amount, it is possible to obtain about 90 thousand tons of non-magnetic fraction, sent to construction, 4 thousand tons of the magnetic fraction for the production of ferrosilicon, iron, and steel, 1.5 tons of microspheres, used as a filler for various products, in production of spheroplastics, road marking thermoplastics, cementing and drilling fluids, lightweight construction ceramics, heat-insulating roasting-free materials and heat-resistant concretes.

ASW recycling will contribute to solving the environmental problems, creation of new jobs, reduction of the environmental fines and obtaining economic benefit. 


\section{Acknowledgments}

The studies were financially supported by the Russian Foundation for Basic Research and Administration of Kemerovo region in the framework of scientific project No. 16-48420871, "r_a”.

\section{References}

1. A.N. Nabokov, G.N. Freiberg, T.P. Shcheblykina, Energetik 10 (2014)

2. A.I. Kalachev, TEK. Strategy of Development 39, 4 (2015)

3. A.A. Salamov, Energetik 10 (2014)

4. A.R. Bogomolov, E.Yu Temnikova, S.A. Shevyrev, A.V. Poltavets and A.S. Sysolyatin, MATEC Web Conf. 37 (2015) 